\title{
Ocular complications of bone marrow transplantation
}

\author{
L C Bray, P J Carey, S J Proctor, R G B Evans, P J Hamilton
}

\begin{abstract}
Forty-one patients who had undergone bone marrow transplantation were examined. Nineteen $(63 \%)$ of the 30 who had received fractionated total body irradiation (TBI) had cataracts in comparison with only $1(9 \%)$ of the 11 non-irradiated patients. No significant differences in steroid therapy were demonstrated between these groups of patients. Dry eyes were observed in eight irradiated patients, seven of whom had preceding graft-versushost disease. Superficial punctate staining of the bulbar conjunctiva was observed in 25 $(83 \%)$ of the irradiated group and, in milder form, in five $(45 \%)$ of the non-irradiated group. Our data suggest that the incidence of cataract following fractionated TBI is influenced not only by the total dose of radiation but also by its rate of administration (defined by midline tissue dose rate and fractionation schedule). In addition dry eyes and conjunctival staining may be exacerbated by TBI, though other aspects of conditioning may also be implicated.
\end{abstract}

Bone marrow transplantation (BMT) is an established treatment for haematological malignancy.' Patients undergoing transplantation receive conditioning treatment which may include total body irradiation (TBI) to eradicate both tumour and recipient marrow cells. The eyes are not normally shielded during TBI because they are a potential site of leukaemia relapse. After the conditioning treatment patients receive either autologous marrow harvested during apparent remission from disease or allogeneic marrow from a tissue matched donor.

Graft-versus-host disease (GVHD) is a major complication of allogeneic $\mathrm{BMT} .^{2-4}$ It results from a reaction of immunocompetent donor marrow cells with recipient (host) tissues, and affects principally the skin, gastrointestinal tract, and liver. It may require treatment with large doses of systemic steroids. Ocular complications are common. ${ }^{5-10}$

Transplant patients are consequently at considerable risk of developing cataracts as a result of their exposure both to $\mathrm{TBI}^{810}$ and to systemic steroids. ${ }^{11}$ The relative risk to these patients of developing cataract is reported to be significantly reduced by either fractionating the TBI or omitting it completely. ${ }^{8}$

The purpose of this study was to determine the incidence of ocular complications in a group of long term survivors of BMT who had received chemotherapeutic tumour ablation either alone or in combination with fractionated TBI.
Patients and methods

The study group consisted of 41 adult patients who underwent BMT for various haematological malignancies (Table 1) at the Royal Victoria Infirmary between March 1983 and September 1989.

\section{TREATMENT GROUPS}

Group 1. Eleven patients underwent autologous BMT following conditioning with a single dose $(3 \mathrm{mg} / \mathrm{kg}$ ) of melphalan, but no irradiation.

Group 2. Thirteen patients underwent autologous BMT following conditioning with a single dose ( $3 \mathrm{mg} / \mathrm{kg}$ ) of melphalan followed by TBI. A total dose of $10.5 \mathrm{~Gy}$ was given as three fractions of 3.5 Gy over 36 hours.

Group 3. Seventeen patients underwent allogeneic BMT following conditioning with two daily doses $(60 \mathrm{mg} / \mathrm{kg})$ of cyclophosphamide followed by TBI. A total dose of $12 \mathrm{~Gy}$ was given as six fractions of $2 \mathrm{~Gy}$ over three days.

TBI was administered by linear accelerator to produce a midline tissue dose rate of $0.25 \mathrm{~Gy} /$ min. The total dose of steroid given to each patient was summated and included both preand post-transplant treatment. Steroid dose was assessed as total number of weeks of therapy irrespective of the dose or relative potency of the steroid used.

\section{OPHTHALMIC EXAMINATION}

This was undertaken by a single observer (LCB) and included best corrected Snellen visual acuity, assessment of precorneal tear film, extent of conjunctival and corneal rose Bengal staining, and a Schirmer's test. ${ }^{12}$ The crystalline lens and fundus were examined following dilatation of the pupils with $1 \%$ tropicamide. The degree of cataract was graded in accordance with the Oxford Clinical Cataract Classification and Grading System. ${ }^{13}$ Keratoconjunctivitis sicca (KCS) was diagnosed if there were poor tear films, superficial punctate staining of the conjunctiva with rose Bengal, and a Schirmer's test of less than $6 \mathrm{~mm} / 5$ minutes. The punctate staining was graded as absent (0), mild (1),

Table 1 Composition of the treatment groups by diagnosis

\begin{tabular}{lllll}
\hline & $A L L$ & $A M L$ & $C M L$ & Lymphoma \\
\hline Group 1 & 0 & 1 & 0 & 10 \\
Group 2 & 9 & 0 & 0 & 4 \\
Group 3 & 4 & 8 & 5 & 0 \\
\hline
\end{tabular}

ALL = acute lymphoblastic leukaemia. $A M L=$ acute myeloid leukaemia. $\mathrm{CML}=$ chronic myeloid leukaemia. 'Lymphoma' includes both Hodgkin's and non-Hodgkin's lymphomas. 
Table 2 Superficial punctate epitheliopathy (SPE) grading distribution for the treatment groups

\begin{tabular}{lllll}
\hline$S P E$ grade & 0 & 1 & 2 & 3 \\
\hline Group 1 & 6 & 2 & 3 & 0 \\
Group 2 & 2 & 3 & 3 & 5 \\
Group 3 & 3 & 3 & 6 & 5 \\
\hline
\end{tabular}

Table 3 Total steroid doses and post-transplant review times for treatment groups

\begin{tabular}{|c|c|c|c|c|}
\hline \multirow[b]{2}{*}{$\begin{array}{l}\text { Group 1 } \\
\text { Group } 2 \\
\text { Group } 3\end{array}$} & \multicolumn{2}{|c|}{$\begin{array}{l}\text { Steroid dose (weeks) } \\
\text { Mean }(S D)\end{array}$} & \multicolumn{2}{|c|}{$\begin{array}{l}\text { Review time (months) } \\
\text { Mean }(S D)\end{array}$} \\
\hline & $\begin{array}{l}25 \cdot 2 \\
21 \cdot 2 \\
20 \cdot 9\end{array}$ & $\begin{array}{r}8 \cdot 8 \\
4 \cdot 4 \\
27 \cdot 5\end{array}$ & $\begin{array}{l}23 \cdot 6 \\
35 \cdot 6 \\
36 \cdot 0\end{array}$ & $\begin{array}{l}13 \cdot 0 \\
20 \cdot 4 \\
24 \cdot 5\end{array}$ \\
\hline
\end{tabular}

Table 4 Total steroid doses and post-transplant follow-up times of those with and without cataracts

\begin{tabular}{llrll}
\hline & \multicolumn{2}{l}{$\begin{array}{l}\text { Steroid dose (weeks) } \\
\text { Mean }\end{array}$} & \multicolumn{2}{l}{ Review time (months) } \\
& & Mean & SD \\
\hline Cataract present & 21.5 & $9 \cdot 7$ & 46.5 & 19.9 \\
Cataract absent & 22.8 & 24.4 & $19 \cdot 3$ & 10.9 \\
Significance (df) & NS & & $\mathrm{p}<0.0001$ & \\
\hline
\end{tabular}

moderate (2), or severe (including confluent areas of epithelial loss (3).

\section{STATISTICAL ANALYSIS}

Comparisons of mean steroid doses and posttransplant review times were made between the three treatment groups and between those patients with and without cataract. Single-tailed Student's $t$ test analysis $(\mathrm{p}<0.05)$ was used to evaluate the effects of increasing post-transplant review time and total steroid dose on the likelihood of cataract formation.

\section{Results}

\section{GROUP 1 (AUTOLOGOUS BMT WITHOUT}

IRRADIATION)

Cataracts were observed in one of the 11 patients in this group. This patient, who was examined at 34 months post-BMT, had grade I posterior subcapsular cataracts. The remaining 10 patients did not have cataracts when examined at six to 45 months post-BMT. None of the patients had dry eyes, though superficial punctate epitheliopathy affecting the inferior bulbar conjunctiva and inferior cornea, was observed in five patients (Table 2).

GROUP 2 (AUTOLOGOUS BMT WITH IRRADIATION) Seven of the 13 patients in this group had cataract (including six of the nine patients with acute lymphoblastic leukaemia) at 36-62 months post-BMT. All cataracts were posterior subcapsular of various grades: I (one patient), II (three patients), IV (one patient), and V (two patients). These last two were sufficiently visually handicapped to require bilateral cataract extractions. The remaining six patients, examined at 6-23 months post-BMT, did not have cataracts. No patients in this group had dry eyes. However, superficial punctate epitheli- opathy of the inferior bulbar conjunctiva and inferior cornea was seen in 11 patients (Table 2).

GROUP 3 (ALLOGENEIC BMT WITH IRRADIATION) Twelve of the 17 patients in this group had cataracts when examined at seven to 84 months post-BMT. All cataracts were posterior subcapsular cataracts of various grades: I (seven patients), II (two patients), and III (three patients). One patient had grade I cataracts at seven months after transplant, having received a total of $16 \mathrm{~g}$ of methylprednisolone during treatment for adult respiratory distress syndrome following BMT. One of those with grade III posterior subcapsular cataracts required cataract extraction. The remaining five patients showed no signs of lens opacity at seven to 33 months post-transplant.

Acute GVHD developed in 12 of these patients, seven of whom had clinical signs of keratoconjunctivitis sicca. Two of these patients had superior tarsal scarring. Chronic GVHD developed in 9 patients and was preceded by acute GVHD in all but one case. Five of these nine had clinical signs of keratoconjunctivitis sicca, but no serious sequelae of dry eyes were observed in any of these patients. Dry eyes were also found in one patient who did not have preceding GVHD. Superficial punctate epitheliopathy affecting the inferior bulbar conjunctiva and inferior cornea were observed in 14 cases (Table 2), and tended to be more severe in patients with GVHD.

There were insufficient data to allow statistical comparisons of steroid doses and post-transplant review times between the three groups. Mean steroid doses for the three groups were broadly similar, as were mean post-transplant review times for autologous and allogeneic grafts receiving TBI (Table 3 ). However, review times for group 3 were somewhat shorter than for the other groups.

Overall, the incidence of cataracts was $63 \%$ (19 of 30) of those patients who received TBI prior to transplantation and 9\% (1 of 11 ) of the nonirradiated patients. There were no significant difference in steroid therapy between those who developed cataracts (including the non-irradiated cataract patient) and those who did not (Table 4). However, post-transplant review times were significantly greater in the former group than in the latter (Table 4).

\section{Discussion}

The association between cataract formation and exposure to ionising radiation was first recognised in the last century. ${ }^{1+}$ The relationship depends not only on total dose used, but on the rate of exposure, as illustrated by Merriam and Focht, ${ }^{15}$ who estimated the minimum dose of radiation required to produce a cataract varied from $2 \mathrm{~Gy}$ if given as a single dose to $5.5 \mathrm{~Gy}$ if given over longer than three months. However, cataract formation was not observed in some patients receiving as much as $11 \mathrm{~Gy}$.

Similarly, dramatic differences in the incidence and severity of cataract were observed in BMT patients receiving TBI at different rates 
of exposure. ${ }^{8}$ In a large comparative study in Seattle, the reported incidence of cataract was $80 \%$ in those receiving single shot TBI (ssTBI) in comparison with $19 \%$ for those given fractionated TBI, and was surprisingly no greater than in those given no TBI. More recently Livesey et $a l^{10}$ found that 15 of 18 patients who received ssTBI had cataracts, as compared with only one of 16 who received either fractionated or no TBI. However, no patient in the latter group had been seen at greater than 18 months after transplantation.

Our finding of a $63 \%$ incidence of cataracts among those patients receiving fractionated TBI contrasts sharply with previous reports. The mean post-transplant review time of those who developed cataracts was 46.5 months in comparison with only 19.3 months for those who did not. In the Seattle study ${ }^{8}$ it was observed that the risk of cataract development increases for the first 30 months after transplantation following fractionated TBI and for 24 months for nonirradiated patients before declining in both cases. Of the 13 patients in our study who received fractionated TBI but did not have cataracts 12 had received their BMT within 30 months of examination. Thus with further follow-up an even greater incidence of cataract might be observed in our irradiated patients. For similar reasons one could argue that the true incidence of cataract among non-irradiated patients may be higher, as only six of the eleven patients in our non-irradiated group had exceeded 24 months after transplantation.

Three additional factors were said by Deeg and colleagues' group ${ }^{8}$ to contribute to the development of cataract in these patients: a history of acute or chronic GVHD, steroid usage after day 100 ('chronic usage'), and an initial diagnosis of acute lymphoblastic leukaemia. They could not separate the importance of GVHD from the use of steroids in these patients because the two were so highly associated. They suggested that the high incidence in patients with acute lymphoblastic leukaemia may be related to the high pre-transplant doses of steroids used, a finding confirmed in a subsequent study. ${ }^{9}$ Among our patients neither steroid therapy nor the frequency of acute lymphoblastic leukaemia appeared to be significantly different between those who developed cataracts and those who did not (though our patient group is small). There was a strong association between the presence of cataract and a history of GVHD, apparently without the excessive use of steroids in this group ( 8 of the 12 patients had received less than the mean steroid dose for the 'cataract present' group as a whole).

In theory the higher incidence of cataract observed in our study could be explained by differences in steroid administration. Comparisons of steroid therapy between studies are difficult to make, as their measurement is inevitably crude, depending not only on total dose but on duration, type, and relative potency of the particular steroid used in each case. We do not believe that the use of steroids in our group was unusually excessive or at variance with accepted practice, rendering this explanation unlikely.
There were differences both in midline tissue dose rate and fractionation schedule of the TBI administration between our study and the Seattle study ${ }^{8}$ which may be significant. All our patients received a midline tissue dose of $0.25 \mathrm{~Gy} / \mathrm{min}$ in comparison to just $0.04-0.08 \mathrm{~Gy} / \mathrm{min}$ for theirs. Secondly, our patients were subjected to TBI fractionated over just $1 \cdot 5-3$ days in comparison with 6-7 days for their patients. We believe that these differences in rate of exposure may significantly contribute to the higher incidence of cataract in our study.

Acute GVHD usually develops within the first three-four weeks after BMT. It occurs with varying severity in more than $50 \%$ of successfully grafted recipients of allogeneic marrow. ${ }^{3}$ Ocular manifestations are reported in $60 \%$ of patients. ${ }^{5}$ The commonest finding is haemorrhagic pseudomembranous conjunctivitis ${ }^{67}$ within the first 90 days after transplantation in patients with severe acute GVHD. It is associated with ulceration of the upper tarsal conjunctiva and results in eventual subtarsal scarring. This late sequela of acute GVHD was observed in two of our patients. Dry eyes were reported in 19 of 25 patients in one series, ${ }^{6}$ and were observed in seven of 12 of our patients with a history of acute GVHD.

Chronic GVHD usually arises 3-6 months following BMT, affecting $25 \%$ to $45 \%$ of the survivors of allogeneic transplant. ${ }^{3}$ It resembles an autoimmune illness, with scleroderma-like involvement of the skin, chronic liver dysfunction, profound immunodeficiency, and Sjøgren-like manifestations involving salivary and lacrimal glands. ${ }^{4}$ Ocular manifestations ${ }^{5-7}$ include superficial punctate keratitis, keratoconjunctivitis sicca, cicatricial lagophthalmos, persistent epithelial defects, and sterile and infectious stromal ulceration. The presence of dry eyes in five of nine of our patients with chronic GVHD is consistent with previous reports.

In our study one case of dry eyes was observed in an allogeneic recipient without a history of GVHD. It is known that higher doses of orbital irradiation, in the region of 32-45 Gy, are usually well tolerated but may be associated with dry eyes. ${ }^{16}$ One study reports three cases of dry eyes in patients receiving only $12 \mathrm{~Gy}^{7}$ Superficial punctate epitheliopathy was an almost universal finding in patients who had undergone TBI and was present, but in less severe form, in nonirradiated patients. It would seem reasonable to ascribe these abnormalities, at least in part, to a toxic effect of TBI on the eye, though its presence in non-irradiated patients suggests that other aspects of the pre-transplant conditioning may also be implicated.

In conclusion, our data suggest that the relationship between irradiation and ocular toxicity is complex, depending not only on total dose but also its rate of administration (that is, midline tissue dose and/or fractionation schedule). Ocular complications may seem trivial in comparison with the serious nature of the systemic disease under treatment, but can assume greater significance in those $55-90 \%$ of patients who become long-term survivors of BMT. Careful scheduling of TBI and the sparing use of steroids are of the utmost importance in minimising these complications. 
1 Thomas ED, Storb R, Clift RA, et al. Bone marrow transplantation. N Eng f Med 1975; 292: 832-43, 895-902.

2 Tutschka PJ, Bortin MM. Graft versus host disease. Transplant Proc 1981; 13: 1267-9.

3 Sullivan KM, Shulman HM, Storb R, et al. Chronic graft versus host disease in 52 patients: adverse natural course and successful treatment with combination immunosuppression. Blood 1981; 57: 267-76.

4 Lawley TJ, Peck GL, Moutsopoulos HM, Gratwohl AA Deisseroth AB. Scleroderma, Siøgren-like syndrome and chronic graft versus host disease. Ann Intern Med 1977; 87: 707-9.

5 Franklin RM, Kenyon KR, Tutschka PJ, Saral R, Green WR, Santos GW. Ocular manifestations of graft versus host disease. Ophthalmology 1983; 90: 4-13.

6 Hirst LW, Jabs DA. Tutschka PJ, Green WR, Santos GW. The eye in bone marrow transplantation. Arch Ophthalmol The eye in bone

7 Jack MK, Jack GM, Sale GE, Shulman HM, Sullivan KM. Ocular manifestations of graft-vs-host disease. Arch Ophthalmol 1983; 101: 1080-4.

8 Deeg HJ, Flournoy Nullivan KM, et al. Cataracts after total body irradiation and marrow transplantation: a sparing effect of dose fractionation. Int $\mathcal{F}$ Radiat Oncol Biol Phys 1984; 10: 957-64.

9 Hoover DL, Smith LEH, Turner SJ, Gelber RD, Sallan SE. Ophthalmic evaluation of survivors of acute lymphoblastic Ophthalmic evaluation of survivi: $151-5$.

10 Livesey SJ, Holmes JA, Whittaker JA. Ocular complicatipns of bone marrow transplantation. Eye 1989; 3: 271-6. C

11 Black RL, Oglesby RB, von Sallman L, Bunim JJ. Posterior subcapsular cataracts induced by corticosteroids in patients with rheumatoid arthritis. $\mathcal{F} A M A$ 1960: 174; 166-71.

12 Duke-Elder S. System of ophthalmology. St Louis: Mosby, 1963: 8: 132 .

13 Sparrow JM, Bron AJ, Brown NAP, Ayliffe W, Hill AR. The Oxford Clinical Cataract Classification and Grading System. Int Ophthalmol 1986; 9: 207-25.

14 Chalupecky $\mathrm{H}$, Ueber die Wirking der Röntgenstrahlen auf das Auge und die Haut. Zentralbl Prakt Augenheilkd 1897; 21: $234,267,886$

15 Merriam GR Focht EF. A clinical study of radiation cataracts and the relationship to dose. AfR 1957; 77: 759-85.

16 Parsons JT, Fitzgerald CR, Hood CI, Ellingwood KE, Bova FJ, Million RR. The effects of irradiation of the eye and optic nerve. Int $\mathcal{F}$ Radiat Oncol Biol Phys 1983; 9: 609-22.

\section{FIFTY YEARS AGO}

Sironi (Milan). Electric cataract from industrial and tempestual discharge. (Cataratta elettrica da corrente industriale e da folgore). Rass. Ital. d'Ottal., September-October, 1939.

Sironi has had the opportunity of seeing cataract due to high tension current and to lightning stroke and comparing the two, he finds the changes identical. $\mathrm{He}$ thinks that in lightning stroke the main discharge often misses the person who is affected only by some of the branches, into which the whole breaks up.
Thus the potential is reduced to something like that of high power industrial current. It has been said that the occurrence of a cataract shows that the discharge must have passed through the head; the author's cases seem to show that this is not necessary since the burns produced at the point of entrance and exit were on the body and leg. The appearance of the opacity may not follow the accident immediately but may be delayed for many months.

HAROLD GRIMSDALE 